hace que la mayoría de los poetas se evidencien como seres agónicos, entre un pasado convertido ya en mito por el discurso del inmigrante cubano y un presente que no le pertenece. De ese pasado nos recuerda el conocido novelista Reinaldo Arenas en uno de sus poemas aquí recogidos: «La precola para la cola que nos da derecho a seguir en la / cola». En total, lo que presentan estos poetas es la conciencia de ser otro, de no pertenecer, como terroríficamente lo expresa Isabel Rivero en su poema, «Los excluidos se muerden las uñas», o también Jorge Valls, quien como prisionero de conciencia ata su experiencia a la de los desaparecidos cuando habla de ese obsesivo tema de la identidad que surge en la literatura del torturado: «Mi rostro es un hueco / y no puedo quitármelo».

Sin embargo, si nos preguntamos cuál es la metáfora significativa del exilio, creo que ahora que tenemos poetas cubanos en Nueva York, la respuesta tendría que ser la soledad. La ciudad de Nueva York impone esta sensación aun cuando no se es exiliado, pues es la ciudad que, a manera de islotes, representa las culturas de los expatriados. Nuestros poetas llevan la soledad hacia un plano metafísico, y en este sentido esta poesía - hasta cierto punto separatista también - conecta con las teclas de la poesía contemporánea. Lo que vocifera la mayoría de los jóvenes poetas de esta antología es la diferencia de ser. Algo sorprende el hecho de que aunque poesía del exilio cubano, incluyéndose a recién llegados a través de Mariel, a ex-prisioneros políticos como Valls y Arenas, esta poesía explora más el acto y la angustia de ser exiliado que la añoranza de lo dejado. El recuerdo y la nostalgia de la Isla, aunque patentes, no alcanza un nivel temático; más importante en este sentido es el ensimismamiento. Es posible que esto esté ligado precisamente al hecho de que los poetas residen en Nueva York.

Todo lo dicho anteriormente rinde total validez a la colección que el señor Felipe Lázaro nos presenta. Aunque existe la posibilidad de que se hayan quedado descarriados algunos poetas callejeros, la presente antología ejemplifica una realidad de nuestras letras, la existencia de una poesía cubana de y en Nueva York.

\title{
Furman University
}

LIBRADA HERNÁNDEZ

\section{Magal. Alabau, Hermana. Madrid: Editorial Betania, 1989.}

Este libro de poemas está dividido en varias secciones, que enfocan sobre una experiencia vivida, pero todo el texto fluye como un poema del recuerdo en el que el discurso poético remite a la literatura de viaje en el tiempo. En este viaje la autora hace un tributo a su hermana, quien se encuentra encerrada/enterrada en el manicomio de Mazorra en la Isla de Cuba. En el poemario converge el recuerdo de la hermana con la experiencia de la poeta exiliada en Nueva York, encerrada/enterrada también en la isla de Manhattan. La poesía será el medio por el cual Alabau explore los viajes del pasado, el de su exilio y el que hacía cada domingo al sanatorio. Ambos viajes son impuestos; el dominical, como tarea de hermana: «Me mandaron aquí, no hubiera venido / me mandaron a cumplir con la obligación, / porque eres mi hermana, porque eres yo de tú y tú de yo», y el viaje al exilio, que resulta en un sentido de culpabilidad al abandonar a la hermana: «Y, sin embargo, yo era la única que entendía / y ese entendimiento el único que te liberaba / y escapé con él».

A través de la escritura, la autora se libera del sentido de culpabilidad y a la vez elimina la enfermedad de la hermana. Este viaje coincide con el regreso odisíaco y está impulsado por un deseo inusitado de retornar a un pasado perdido en el recuerdo: 
Cuba es un baúl amarrado

lleno de prohibiciones, una caja que no abro

porque salen todas, una a una maldiciones.

Una vez abierto el baúl y el pasado hecho posible, la muerte se hace evidente tanto en la vida de la hermana en Cuba como en la de la ambulante del subway neoyorquino. Estos viajes convergentes y entretejidos en el discurso poético cobran así un sentido elegíaco que nos recuerda las coplas de Manrique. Sin embargo, en estos poemas se vuelve la vista atrás para revivir un tiempo pasado que no fue mejor; se trata de un tiempo pasado en que el mundo caótico de la hermana se enreda y coincide con el mundo tumultuoso, confuso y discordante de la poeta. Por otra parte, el viaje nos remite al mito de Orfeo y Eurídice en una nueva mitología en que se recupera la infancia perdida en la poesía misma.

Puesto que el poemario está estructurado en forma de viaje, las varias secciones en que se divide forman como escalas a través de las cuales la persona poética busca las raíces de la identidad para completar su personalidad. En estas escalas Magali Alabau anima todo el pasado, desde los juegos de la niñez con su hermana, sus visitas al manicomio, la compleja relación con los padres, sus viajes neoyorquinos, hasta la angustia existencial del exilio y el vacío de la vida diaria en la gran ciudad. La autora, mostrando el efecto de la separación de las hermanas, hace un esfuerzo por completar ese viaje poético con la recuperación imaginaria de la hermana. Esta resucita en el poema y entra en el mundo de la poeta: «La soga de mi cama / te servirá de escalera. / Sonríe, hermana mía. / Estás en Nueva York». Al final se comenta precisamente que la superación del abandono, el escape y la culpabilidad se lleva a cabo dentro del texto poético. Es en este texto poético donde las dos hermanas vuelven a darse las manos en una despedida que se torna en un reencuentro: «Sólo manos darnos en esta despedida, / solos dedos reconocen nuestra unión».

En total, el libro encompasa dos vidas aisladas tanto en el tiempo como en el espacio: la hermana, aislada en el pasado en la Cuba del recuerdo, casi mítica y mitificada en el poemario y aislada también en la soledad y abandono del sanatorio; la poeta, abandonada en el presente entre la multitud, «las hordas», en la soledad de Nueva York.

En el discurso poético se hace eco también la agonía de vivir en la gran ciudad de Nueva York. En cierto modo, la aglomeración metropolitana sin sentido que enajena al ser humano de sus raíces es también el acicate que mueve a la autora y la hace reafirmarse a la vida: «Mientras huelo las hordas, / más inmune / este anhelo». La ciudad misma despierta el ansia de búsqueda y en su absurda realidad metálica de trenes y borrachos de sueño da lugar al encuentro con el pasado. El mundo poético del texto contradice todo encuentro en un tiempo lineal y, por lo mismo, el tiempo se torna en un tiempo fuera del tiempo, un presente y un pasado fuera del presente y del pasado; nada indica que un grupo ha de encontrarse:

He registrado la ciudad.

Todos en su sitio, sin moverse.

La noche escupe miedo y todos oyen.

No hay quien pueda callarnos. Cada planta arrancada

es el otro. Cada ultraje repercute en esta cama

donde un hombre y una mujer comieron.

Los árboles de aquel campo en que nos dejaron

repiten en mi cuarto: memoria viva. 
En tanto que el poemario es una resucitación de lo que ha sido enterrado en la memoria, el cuadro reproducido en la portada y que aparece, literalmente, detrás del texto poético, ilumina el sentido del viaje y funciona como metáfora del texto poético; en la pintura de Sylvia Baldeón, «Anamnesis», encontramos la figura de la hermana resucitada en la memoria y el historial de su enfermedad recreado en la escritura.

En cuanto al lenguaje, en este poemario se destaca una complicidad entre la palabra poética y la desintegración de un mundo ordenado. Aunque el poemario apunta hacia la conjugación de un pasado y un presente, el mundo en que éste se da es un espacio caótico en que la lucha por el orden se torna absurda, puesto que el orden no es parte del universo palpable, sino del discurso poético. Sólo en la transgresión de lo real puede traspasarse el caos. El lenguaje desgaja el tiempo, la memoria y derrumba la pared entre ese universo palpable neoyorquino y el místico universo textual en que se juntan las hermanas. De ahí que en la palabra escrita el pasado cobre sentido en el presente. La palabra aquí hace resonar lo inefable y descascara el dolor oprimido. El lenguaje es el medio para desenmascarar los recuerdos y el sentido de ese universo enterrado. El poemario está cargado de imágenes que presentan el abandono, la soledad y la agonía existencial de una manera desgarradora. A la misma vez, la metáfora de aislamiento que es central al texto pasa de la palabra escrita a la imagen visual recreada en el cuadro de Baldeón.

\section{Furman University}

LiBRADA HERnÁndeZ

Perla Rozencvaig, Reinaldo Arenas: Narrativa de transgresión. Oaxaca: Editorial Oasis, 1986.

Este primer libro de Perla Rozencvaig, original en concepto y en metodología, viene a llenar un vacío en la nueva crítica hispanoamericana: la obra de Reinaldo Arenas, rica en problemas de intertextualidad, compleja en su estructura y densa en sus niveles de significado, no había recibido, hasta ahora, un enfoque crítico tan completo y detallado. Dividido en seis capítulos, el libro dedica los dos primeros a El mundo alucinante (1969), y los otros cuatro a las tres otras novelas del escritor (parte de su anunciada pentagonía sobre aspectos políticos y sociales en Cuba a partir de los años cincuenta); una bibliografía complementa el volumen.

La «Nota preliminar» declara el objetivo principal del libro: «demostrar que las novelas de Arenas... constituyen un cuerpo orgánico por el que se filtra una visión de mundo en correspondencia con una ideología fija: la constante búsqueda de un espacio liberador, sede de incesantes transgresiones». Tal concepto «orgánico» le permite a la autora concentrarse en cada novela independientemente, pero sin perder de vista su propósito, establecer la validez de una «narrativa de transgresión». El primer capítulo demuestra cómo la intertextualidad ideológica en $E l$ mundo..., conseguida a través de «mecanismos de fragmentación, confusión, desorden y multiplicidad», establece conexiones directas entre la controvertida y revolucionaria figura histórica y literaria de fray Servando Teresa de Mier y el escritor Reinaldo Arenas, «testigo participante de la nueva realidad cubana». El segundo analiza la intertextualidad paródica a través de la transmutación del andrógino personaje de Virginia Woolf, Orlando (en su novela del mismo nombre), y sus funciones en el texto de Arenas.

En los capítulos III y IV se discuten dos aspectos fundamentales de Celestino antes del alba (1967); el tercero ofrece un detallado análisis del personaje infantil como narrador y protagonista, y el cuarto estudia la función del doble (Celestino), creación del narrador/protagonista. Rozencvaig sugiere que a través de esta «transgresión de la realidad empírica», el escritor propone un modelo de la escritura como subversión, y prosigue a desarrollar esta idea en el capítulo V, dedicado a El palacio de las blanquísimas mofetas (1980). Como el 